\title{
Father Early Engagement Behaviors and Infant Low Birth Weight
}

\author{
Shawna J. Lee ${ }^{1,3} \cdot$ Diana T. Sanchez ${ }^{2} \cdot$ Andrew Grogan-Kaylor ${ }^{1}$. Joyce Y. Lee $\cdot$ Analia Albuja $^{2}$
}

๑) Springer Science+Business Media, LLC, part of Springer Nature 2018

\begin{abstract}
Objective To examine the association of father early engagement behaviors and infant low birth weight (LBW) among unmarried, urban couples. Methods Participants were from the Fragile Families and Child Wellbeing Study, a birth-cohort study of urban families. We conducted cross-sectional analyses of data from interviews with unmarried mothers and fathers $(\mathrm{N}=2726)$ that took place at the time of their child's birth. Early engagement behaviors were based on fathers' self-report of whether during the pregnancy they gave mothers money to buy things for the baby, helped in other ways like providing transportation to prenatal clinics, and attended the birth. Results Most (68.9\%) fathers engaged in all three early engagement behaviors; $22 \%$ engaged in 2 behaviors; and $9.1 \%$ engaged in 1 or 0 early engagement behaviors. LBW more than doubled when comparing infants of fathers who engaged in all three early engagement behaviors (9.6\% predicted probability of LBW) to those fathers who engaged in no early engagement behaviors (over $22 \%$ predicted probability of LBW). Conclusion Infant and maternal health may benefit from intervention to encourage positive father engagement during pregnancy.
\end{abstract}

Keywords Perinatal period $\cdot$ Father-child relations $\cdot$ Infancy $\cdot$ Fathers $\cdot$ Fathering

$\begin{array}{ll}\text { Abbreviations } \\ \text { AOR } & \text { Adjusted odds ratio } \\ \text { FFCWS } & \text { Fragile Families and Child Wellbeing Study } \\ \text { LBW } & \text { Low birth weight } \\ \text { US } & \text { United States } \\ \text { VIF } & \text { Variance inflation factor } \\ \text { WHO } & \text { World Health Organization }\end{array}$

\section{Significance}

What is already known on this subject? Low father involvement is associated with negative infant health outcomes, including greater risk of low birth weight. Measures of father involvement are often limited to marital status or fathers' absence/presence.

What this study adds? This study examines father involvement among unmarried parents measured by fathers' reports of engagement in instrumental and social support to the

Shawna J. Lee

shawnal@umich.edu

1 University of Michigan, Ann Arbor, USA

2 Rutgers University, New Brunswick, NJ, USA

3 University of Michigan School of Social Work, 1080 South University Avenue, Ann Arbor, MI 48109, USA mother during the perinatal period. Higher levels of father early engagement were associated with lowered risk for infant low birth weight. Fathers' self-reports of his early engagement were a stronger predictor of infant low birth weight than mothers' reports of fathers' early engagement behaviors.

\section{Introduction}

In 2013, 8.02\% of all infants were born at low birth weight (LBW; <2500 g, or 5 lbs $8 \mathrm{oz}$ ) (Martin et al. 2015). Low birth weight (LBW) is an early indicator of negative infant health outcomes and subsequent poorer adjustment. For example, LBW is a primary cause of infant mortality (Malin et al. 2014; Mathews and MacDorman 2013) and is linked to children's poorer developmental (Boardman et al. 2002) and educational (Conley and Bennett 2000) outcomes. Factors such as maternal tobacco use (Chamberlain et al. 2013), low socioeconomic status (Aizer and Currie 2014), nativity status (Taylor and Sarathchandra 2015), and racial or ethnic minority status (Hamilton et al. 2012; Ma 2008; Ngui et al. 2009) are associated with greater risk for LBW.

Relatively few studies have explored paternal factors that are associated with perinatal infant health (Alio et al. 2011; Bond 2010; Lu et al. 2010; Misra et al. 2010). Yet, mounting 
evidence points to the ways in which father involvement is associated with the maternal wellbeing and enhanced health of their children (Bloch et al. 2010; Dubowitz et al. 2001; Jeynes 2014; Waldfogel et al. 2010). Research to date has often focused on the association of infant LBW and low father involvement, operationalized by nonmarital birth. By this measure, low father involvement is common in the US. In 2013, 40.6\% of all infant births were to unmarried women (Martin et al. 2015). In 2002, the rate of LBW among unmarried women was $9.9 \%$, compared to $6.7 \%$ among married women (Reichman et al. 2008). Another measure of low father involvement is having no father named on the birth certificate. Rates of LBW and preterm birth were also higher when fathers' information was missing from the birth record (Alio et al. 2011; Ngui et al. 2009; Tan et al. 2004).

However, marital status or fathers' absence on birth certificate records is an imprecise assessment of father involvement. More than $80 \%$ of nonmarital births in the US were to romantically involved couples, and the majority of these parents were cohabiting at the time of their child's birth (Carlson and McLanahan 2002; McLanahan et al. 2003). Most unmarried parents have strong expectations for marriage and father involvement (Gibson-Davis et al. 2005). Thus, more research is needed to understand how variation in paternal involvement among unmarried couples may be associated with outcomes such as LBW.

We focus on how unmarried fathers may support their partner during pregnancy. An ecological perspective (Bronfenbrenner 1979) suggests fathers' early engagement and support behaviors have both direct and indirect effects on infant health outcomes (Lu et al. 2010). For example, a partner may provide tangible resources, such as income, that contribute to better maternal and infant health, since low income may negatively affect infant health-particularly among already disadvantaged mothers (Aizer and Currie 2014). A supportive partner may indirectly promote infant health by reducing maternal stress, which is common among disadvantaged mothers (Aizer and Currie 2014; Bloch et al. 2010; Dunkel-Schetter and Tanner 2012). Such positive father engagement has also been linked to reduced LBW (Hobel et al. 2008; Hux et al. 2014; Witt et al. 2014). One study of an at-risk sample of depressed teen mothers showed that paternal engagement has positive effects in reducing infant distress (Lewin et al. 2015).

The current study addresses several gaps in knowledge. Epidemiological studies suggest that low father involvement is associated with greater risk for LBW, but these studies mainly operationalize involvement through the father's presence or absence and thus do not capture unmarried fathers' supportive behaviors to his partner during pregnancy. This study tests whether fathers' early engagement and supportive behaviors are associated with LBW. Analyses focus on unmarried parents, to better understand associations of fathers' early engagement and supportive behaviors in a sample of "fragile" families whose infants are at highest risk for LBW. A central hypothesis is that father involvement may influence birth outcomes via support behaviors to the mother.

As noted previously, numerous demographic and socioeconomic factors are linked to low father involvement and LBW. The analyses presented herein control for factors such as parental age (Alio et al. 2011; Reichman et al. 2008; Reichman and Teitler 2006), socioeconomic status (Aizer and Currie 2014), race and ethnicity (Fulda et al. 2014; Hamilton et al. 2012; Ma 2008; Ngui et al. 2009), and nativity status (Taylor and Sarathchandra 2015). Given the association of maternal (Aizer and Currie 2014) and paternal (Stotts et al. 2013) health behaviors and LBW, analyses also controlled for tobacco use (Chamberlain et al. 2013) and maternal self-rated general health (DeSalvo et al. 2006; Idler and Angel 1990; Idler and Benyamini 1997). Hypotheses were guided by the ecological perspective (Bronfenbrenner 1979), thus analyses controlled for aspects of the household environment such as greater number of children in the household. Not all forms of father involvement are positive; therefore, to better isolate the potential influence of fathers' early engagement behaviors, analyses herein controlled for dimensions of parental relationship quality. We also controlled for important sociodemographic characteristics such as race and ethnicity and education level of the parent (Castillo et al. 2011).

\section{Methods}

\section{Data and Participants}

Data are from the Fragile Families and Child Wellbeing Study (FFCWS), a birth-cohort study conducted in 20 US cities. A detailed description of the sample is published elsewhere (Reichman et al. 2001). The current study uses selfreported data from baseline interviews that were conducted from 1998 to 2000 with mothers $(\mathrm{N}=4898)$ and fathers $(\mathrm{N}=3830)$ at the time of the child's birth. The analytic sample herein includes singleton births to unmarried parents, the majority of whom (mothers 55\%; fathers 60\%) had at least one other biological child at the baseline interview. There were 3711 unmarried parents in the baseline FFCWS sample. Because we used self-reported information from fathers, both parents had to participate in the baseline interview to be in the analytic sample. Moreover, we included only singleton births $(\mathrm{N}=2726)$, because multiple birth infants are more likely to be LBW or preterm compared to singleton births (Martin et al. 2015). We excluded fathers who were incarcerated or who did not provide data on incarceration $(\mathrm{N}=132)$; cases with no birth weight data $(\mathrm{N}=23)$; and families who 
did not complete all measures $(\mathrm{N}=180)$, leaving a final analytic sample of 2391 unmarried parent families.

\section{Measures and Analysis Plan}

\section{Low Birth Weight}

Consistent with the WHO definition, LBW infants are defined as weighing less than $5.5 \mathrm{lbs}(<2500 \mathrm{~g}) ; 11 \%$ of singleton births in this sample were LBW.

\section{Father Early Engagement Behavior}

Father early engagement behavior was measured by the sum (from 0 to 3 ) of "yes" answers to three questions, selfreported by fathers: "During [baby's mother's] pregnancy, did you give her money to buy things for the baby/babies?" "Did you help in other ways, such as providing transportation to the pre-natal clinic or helping with chores?" and "Were you present at the birth?"

\section{Confounders}

\section{Relationship Status}

Fathers and mothers indicated whether they were romantically involved and living together, but not married (cohabiting); in a relationship but not living together (non-cohabiting); or unstable/no relationship.

\section{Relationship Quality}

For relational engagement ( $\alpha=.65$ ) mothers reported (no/ yes) whether the couple engaged in activities before the birth (e.g., visited friends, ate at restaurant). A summed composite was created; higher scores indicate greater engagement. For relational agreement $(\alpha=.65)$, mothers reported how much the couple disagree (e.g., sex, drinking/ drug use, money) from 1 (often) to 3 (never), with higher mean scores indicating greater agreement. For relational support $(\alpha=.62)$, mothers reported fathers' support (e.g., he expressed affection or love for you) from 1 (never) to 3 (often), with higher mean scores indicating greater support. Mother reported, in years, how long they had known the father.

\section{Self-rated Health (DeSalvo et al. 2006; Idler and Angel 1990)}

Mothers self-reported, "In general, how is your health? Would you say it is..." rated from 1 (poor) to 5 (excellent).

\section{Month Started Prenatal Care}

Mothers self-reported which pregnancy month they began prenatal care. Higher scores corresponded with a delay of prenatal care initiation.

\section{Parental Substance Use}

Fathers self-reported cigarette, alcohol, and drug use in the past 3 months. Mothers self-reported the same behaviors during the pregnancy. Although the time frame differed for mothers and fathers, the response categories were the same: cigarette use was rated from 1 ( 2 or more packs a day) to 4 (none); drug and alcohol use was rated from 1 (nearly every day) to 5 (never), recoded for analysis so higher scores correspond with more use.

\section{Demographics}

Demographics included parents' age, education level, race/ ethnicity, nativity status/foreign born, annual household income, and number of children in household.

\section{Statistical Analysis Plan}

Data were analyzed with SPSS Version 23.0 (IBM Corporation 2014). Table 1 presents the way in which the analytic sample $(\mathrm{N}=2391)$ differed from those who were excluded $(\mathrm{N}=335)$ from the sample due to the aforementioned study criteria (e.g., missing data or incarceration). Table 2 presents group differences by LBW status. Table 3 presents multivariate logistic regression models that examined whether father early engagement behaviors were associated with LBW. Model 1 included health behaviors that are known risk factors associated with LBW. Model 2 added demographic characteristics. To test for multicollinearity, we examined the variance inflation factor (VIF) for the models in Table 3. All VIFs for continuous predictor variables were below 2.5. Categorical variables (e.g., relationship status, race and ethnicity) had higher VIFs. Thus, we conducted sensitivity analyses that excluded the categorical variables with high VIFs. Excluding these variables did not significantly alter the results (i.e., father early engagement behaviors were associated with LBW with similar point estimates and effect sizes). Therefore, we retained both mothers' and fathers' variables in the models. Because odds ratios cannot be directly interpreted as statements about probabilities (Viera 2008), as a final step we calculated the predicted probability of LBW for each additional engagement behavior (Long and Freese 2005). 
Table 1 Attrition by family characteristics at baseline $(\mathrm{N}=2726)$

\begin{tabular}{|c|c|c|c|}
\hline Variable (range) & $\begin{array}{l}\text { Missing }(12 \%)(\mathrm{N}=335) \\
\text { Mean }(\mathrm{SD}) \text { or } \%\end{array}$ & $\begin{array}{l}\text { Included }(88 \%)(\mathrm{N}=2391) \\
\text { Mean }(\mathrm{SD}) \text { or } \%\end{array}$ & $P$ value \\
\hline Low birth weight $(\mathrm{LBW})^{\mathrm{a}, \mathrm{b}}$ & $14 \%$ & $11 \%$ & .07 \\
\hline Father early engagement (range $0-3$ ) & $2.08(1.04)$ & $2.57(0.73)$ & $<.001$ \\
\hline \multicolumn{4}{|l|}{ Relationship quality } \\
\hline \multicolumn{4}{|l|}{ Relationship status $^{\mathrm{a}}$} \\
\hline Unstable or no relationship & $17 \%$ & $8 \%$ & $<.001$ \\
\hline Cohabitating relationship & $45 \%$ & $59 \%$ & \\
\hline Non-cohabitating relationship & $38 \%$ & $33 \%$ & \\
\hline Years known father $(0-36)$ & $3.59(4.03)$ & $3.81(4.19)$ & .37 \\
\hline Relational agreement (1-3) & $2.51(0.45)$ & $2.54(0.40)$ & .20 \\
\hline Relational engagement $(0-4)$ & $2.35(1.56)$ & $2.96(1.20)$ & $<.001$ \\
\hline Relational support (1-3) & $2.57(0.40)$ & $2.64(0.37)$ & .004 \\
\hline \multicolumn{4}{|l|}{ Maternal prenatal health } \\
\hline Self-rated health $(1-5)$ & $3.81(1.00)$ & $3.84(0.97)$ & .53 \\
\hline Prenatal smoking (1-4) & $1.38(0.58)$ & $1.25(0.51)$ & $<.001$ \\
\hline Prenatal alcohol use (1-5) & $1.21(0.60)$ & $1.12(0.42)$ & .001 \\
\hline Prenatal drug use (1-5) & $1.26(0.77)$ & $1.09(0.45)$ & $<.001$ \\
\hline Month started prenatal care $(0-9)$ & $2.88(1.69)$ & $2.53(1.47)$ & $<.001$ \\
\hline \multicolumn{4}{|l|}{ Paternal prenatal health } \\
\hline Paternal tobacco use $(1-4)$ & $1.60(0.74)$ & $1.60(0.76)$ & .99 \\
\hline Paternal alcohol use (1-5) & $2.19(1.22)$ & $2.37(1.14)$ & .01 \\
\hline Paternal drug use (1-5) & $1.40(0.98)$ & $1.36(0.91)$ & .42 \\
\hline \multicolumn{4}{|c|}{ Demographic and household characteristics } \\
\hline \# of other children in hhld $(0-8)$ & $1.47(1.42)$ & $1.26(1.32)$ & .01 \\
\hline Mother's age (15-43) & $23.89(5.75)$ & $23.78(5.51)$ & .75 \\
\hline Father's age (15-53) & $27.21(7.47)$ & $26.39(6.86)$ & .04 \\
\hline Mother's education & $1.65(0.83)$ & $1.86(0.89)$ & $<.001$ \\
\hline Father's education & $1.73(0.79)$ & $1.90(0.84)$ & .001 \\
\hline Annual hhld income $(\$ 0-125,975)$ & $20,670(20,880)$ & $25,563(23,342)$ & $<.001$ \\
\hline Foreign-born mother ${ }^{a, b}$ & $11 \%$ & $13 \%$ & .19 \\
\hline Foreign-born father ${ }^{a, b}$ & $11 \%$ & $15 \%$ & .05 \\
\hline Mother's race/ethnicity ${ }^{\mathrm{a}}$ & & & .02 \\
\hline White & $12 \%$ & $16 \%$ & \\
\hline Black & $61 \%$ & $53 \%$ & \\
\hline Hispanic & $26 \%$ & $29 \%$ & \\
\hline Other & $1 \%$ & $3 \%$ & \\
\hline Father's race/ethnicity ${ }^{\mathrm{a}}$ & & & .006 \\
\hline White & $8 \%$ & $12 \%$ & \\
\hline Black & $64 \%$ & $54 \%$ & \\
\hline Hispanic & $25 \%$ & $30 \%$ & \\
\hline Other & $3 \%$ & $4 \%$ & \\
\hline
\end{tabular}

All analyses were conducted with independent t-test with the exception of those labeled with letter subscripts

$S D$ standard deviation, hhld household

${ }^{\mathrm{a}} \mathrm{Chi}$-square analyses were conducted

${ }^{\mathrm{b}}$ Dichotomous variable coded 0,1 
Table 2 Family characteristics at baseline by LBW Status $(\mathrm{N}=2391)$

\begin{tabular}{|c|c|c|c|}
\hline Variable & $\begin{array}{l}\text { LBW }(11 \%) \\
\text { Mean (SD) or \% }\end{array}$ & $\begin{array}{l}\text { Normal birth weight ( } 89 \%) \\
\text { Mean (SD) or } \%\end{array}$ & $P$ value \\
\hline Paternal perinatal engagement & $2.38(0.86)$ & $2.60(0.71)$ & $<.001$ \\
\hline \multicolumn{4}{|l|}{ Relationship quality } \\
\hline \multicolumn{4}{|l|}{ Relationship status $^{\mathrm{a}}$} \\
\hline Unstable or no relationship & $10.3 \%$ & $7.6 \%$ & $<.02$ \\
\hline Cohabitating relationship & $51.7 \%$ & $60.4 \%$ & \\
\hline Non-cohabitating relationship & $38 \%$ & $32 \%$ & \\
\hline Years known father & $3.57(4.27)$ & $3.84(4.18)$ & .31 \\
\hline Relational agreement & $2.50(0.44)$ & $2.54(0.39)$ & .07 \\
\hline Relational engagement & $2.82(1.30)$ & $2.98(1.19)$ & .03 \\
\hline Relational support & $2.61(0.39)$ & $2.64(0.37)$ & .15 \\
\hline \multicolumn{4}{|l|}{ Maternal prenatal health } \\
\hline Self-rated health & $3.72(1.03)$ & $3.86(0.96)$ & $<.03$ \\
\hline Prenatal smoking & $1.40(0.59)$ & $1.23(0.49)$ & $<.001$ \\
\hline Prenatal alcohol use & $1.23(0.62)$ & $1.11(0.39)$ & $<.001$ \\
\hline Prenatal drug use & $1.20(0.67)$ & $1.08(0.41)$ & $<.001$ \\
\hline Month started prenatal care & $2.69(1.52)$ & $2.51(1.46)$ & .06 \\
\hline \multicolumn{4}{|l|}{ Paternal prenatal health } \\
\hline Paternal tobacco use & $1.78(0.82)$ & $1.58(0.75)$ & $<.001$ \\
\hline Paternal alcohol use & $2.53(1.17)$ & $2.35(1.14)$ & $<.02$ \\
\hline Paternal drug use & $1.45(1.00)$ & $1.35(0.90)$ & .10 \\
\hline \multicolumn{4}{|l|}{ Demographic and characteristics } \\
\hline \# of other children in hhld & $1.22(1.32)$ & $1.26(1.32)$ & .63 \\
\hline Mother's age & $24.15(5.97)$ & $23.74(5.45)$ & .24 \\
\hline Father's age & $26.76(7.63)$ & $26.34(6.76)$ & .34 \\
\hline Mother's education & $1.81(0.88)$ & $1.87(0.89)$ & .30 \\
\hline Father's education & $1.83(0.80)$ & $1.90(0.84)$ & .19 \\
\hline Annual hhld income & $23,569(20,497)$ & $25,818(23,674)$ & .14 \\
\hline Foreign-born mother $^{\mathrm{a}}$ & $7 \%$ & $14.1 \%$ & .001 \\
\hline Foreign-born father ${ }^{\mathrm{a}}$ & $8.1 \%$ & $16.4 \%$ & $<.001$ \\
\hline Mother's race/ethnicity ${ }^{\mathrm{a}}$ & & & $<.001$ \\
\hline White & $15.5 \%$ & $15.6 \%$ & \\
\hline Black & $65.3 \%$ & $51 \%$ & \\
\hline Hispanic & $17 \%$ & $30.3 \%$ & \\
\hline Other & $2.2 \%$ & $3.1 \%$ & \\
\hline Father's race/ethnicity ${ }^{a}$ & & & $<.001$ \\
\hline White & $12.9 \%$ & $12.2 \%$ & \\
\hline Black & $66.8 \%$ & $52.7 \%$ & \\
\hline Hispanic & $16.2 \%$ & $31.5 \%$ & \\
\hline Other & $4.1 \%$ & $3.6 \%$ & \\
\hline
\end{tabular}

All analyses were conducted with independent t-test with the exception of those labeled with letter subscripts

hhld household, $L B W$ low birth weight, $S D$ standard deviation

${ }^{\mathrm{a}} \mathrm{Chi}$-square analyses were conducted

\section{Results}

Most fathers (68.9\%) engaged in all three early engagement behaviors; $22 \%$ in two early engagement behaviors; $6.5 \%$ in one early engagement behavior; and $2.6 \%$ in no early engagement behaviors. The median response for father early engagement for the analytic sample was 3.00, and the interquartile range of 1.00. Eleven percentage of the infants in the current analytic sample were born at LBW $(<5.5 \mathrm{lbs}$. or $2500 \mathrm{~g}$ ) (Table 2). Bivariate results (Table 2) indicated 
Table 3 AORs for father early engagement and other factors predicting risk for LBW status $(\mathrm{N}=2391)$

\begin{tabular}{|c|c|c|c|c|}
\hline \multirow[t]{2}{*}{ Variables } & \multicolumn{2}{|l|}{ Model 1} & \multicolumn{2}{|l|}{ Model 2} \\
\hline & AOR $(95 \% \mathrm{CI})$ & $P$ value & AOR $(95 \% \mathrm{CI})$ & $P$ value \\
\hline Paternal perinatal engagement & $0.74(0.62-0.89)$ & .001 & $0.75(0.62-0.90)$ & .002 \\
\hline \multicolumn{5}{|l|}{ Relationship quality } \\
\hline \multicolumn{5}{|l|}{ Relationship status } \\
\hline Unstable or no relationship & - & - & - & - \\
\hline Cohabitating relationship & $1.05(0.62-1.76)$ & .87 & $1.00(0.59-1.70)$ & .99 \\
\hline Non-cohabitating relationship & $0.83(0.51-1.36)$ & .46 & $0.89(0.54-1.48)$ & .66 \\
\hline Years known father & $0.98(0.95-1.01)$ & .22 & $0.97(0.94-1.01)$ & .15 \\
\hline Relational agreements & $1.07(0.75-1.51)$ & .72 & $1.15(0.80-1.65)$ & .44 \\
\hline Relational engagement & $0.98(0.87-1.10)$ & .74 & $0.98(0.87-1.10)$ & .70 \\
\hline Relational support & $1.18(0.80-1.76)$ & .41 & $1.26(0.84-1.88)$ & .26 \\
\hline \multicolumn{5}{|l|}{ Maternal prenatal health } \\
\hline Self-rated health & $0.88(0.77-1.01)$ & .07 & $0.86(0.75-0.99)$ & .03 \\
\hline Prenatal smoking & $1.40(1.10-1.78)$ & .006 & $1.35(1.04-1.75)$ & .02 \\
\hline Prenatal alcohol use & $1.30(1.01-1.67)$ & .04 & $1.25(0.96-1.62)$ & .09 \\
\hline Prenatal drug use & $1.15(0.90-1.46)$ & .26 & $1.11(0.87-1.42)$ & .40 \\
\hline Month started prenatal care & $1.03(0.95-1.13)$ & .44 & $1.04(0.96-1.14)$ & .35 \\
\hline \multicolumn{5}{|l|}{ Paternal prenatal health } \\
\hline Paternal tobacco use & $1.23(1.05-1.46)$ & .01 & $1.21(1.01-1.43)$ & $<.04$ \\
\hline Paternal alcohol use & $1.08(0.96-1.21)$ & .19 & $1.09(0.97-1.22)$ & .16 \\
\hline Paternal drug use & $1.02(0.89-1.16)$ & .82 & $0.99(0.86-1.14)$ & .86 \\
\hline \multicolumn{5}{|c|}{ Demographic and household characteristics } \\
\hline \# of other children in hhld & & & $0.89(0.80-0.99)$ & .03 \\
\hline Mother's age & & & $1.03(0.99-1.07)$ & .11 \\
\hline Father's age & & & $0.99(0.96-1.02)$ & .37 \\
\hline Mother's education & & & $0.95(0.79-1.13)$ & .54 \\
\hline Father's education & & & $0.92(0.77-1.11)$ & .39 \\
\hline Annual hhld income & & & $1.00(1.00-1.00)$ & .87 \\
\hline Foreign-born mother & & & $1.11(0.57-2.18)$ & .76 \\
\hline Foreign-born father & & & $1.32(0.70-2.47)$ & .39 \\
\hline Mother's race/ ethnicity: White & & & - & - \\
\hline Black & & & $0.77(0.43-1.38)$ & .37 \\
\hline Hispanic & & & $1.02(0.54-1.92)$ & .94 \\
\hline Other & & & $1.14(0.42-3.12)$ & .80 \\
\hline Father's race/ethnicity: White & & & - & - \\
\hline Black & & & $0.88(0.47-1.67)$ & .70 \\
\hline Hispanic & & & $1.44(0.74-2.82)$ & .28 \\
\hline Other & & & $0.75(0.32-1.75)$ & .50 \\
\hline
\end{tabular}

$\mathrm{N}$ dash denote reference group for categorical variables

$A O R$ adjusted odds ratio, $C I$ confidence interval, hhld household, $L B W$ low birth weight that lower levels of father early engagement behaviors were correlated with greater occurrence of LBW. Furthermore, mothers of LBW babies reported lower levels of relational engagement; lower levels of self-rated health; and more smoking, alcohol use, and drug use. Similarly, fathers of LBW infants reported greater smoking and alcohol use.

Table 3 presents the adjusted odds ratios (AORs) obtained from multivariate logistic regression models that examined whether father early engagement behaviors were associated with child LBW. In Model 1, each additional early engagement behavior was associated with a $26 \%$ decrease in the AOR of LBW (AOR $=0.74,95 \%$ CI $[0.62$, 0.89 ], $p=.001$ ), while controlling for relationship variables, maternal health, and paternal health. In Model 2, the addition of demographic variables did not substantially change the association of father early engagement behaviors to $\mathrm{LBW}(\mathrm{AOR}=0.75,95 \% \mathrm{CI}[0.62,0.90], p=.002)$. 
In Model 2, the sum of father early engagement behaviors was associated with a $25 \%$ decrease in the AORs of LBW.

The regression model (Table 3 ) results provided an estimate of the relationship of each independent variable with the AORs of LBW. However, because odds ratios are not direct statements about probabilities, we calculated predicted probabilities of the association of father early engagement behaviors and LBW (Fig. 1). Results indicated that fathers with 0 early engagement behaviors had a $22.7 \%$ predicted probability of LBW; fathers with 1 early engagement behavior had a $17.3 \%$ predicted probability of LBW; fathers with 2 early engagement behaviors had a $13.8 \%$ predicted probability of LBW; and fathers with all 3 early engagement behaviors had the lowest $(9.6 \%)$ predicted probability of LBW. This change in the predicted probability of LBW can be interpreted in relative terms. In this sample of atrisk unmarried parents, being in a non-engaged father family (i.e., those fathers who participated in 0 behaviors) was associated with more than twice the predicted probability of LBW when compared to fathers who participated in three early engagement behaviors.

\section{Sensitivity Analysis}

One early engagement behavior used in our measure (i.e., being present at birth) may have been discouraged or impossible for some fathers due to unexpected birth complications. Furthermore, because of its timing (immediately preceeding the infant's birth), being present at the birth is best viewed as an indirect assessment of early engagement. To address this concern, we conducted additional sensitivity analyses to examine whether findings were robust to this item by creating an alternative measure of father early engagement behaviors that excluded this event. Using this modified measure and adjusting for the covariate variables, our independent variable assessing fathers' engagement was significantly associated with LBW in Model 1 (AOR $=0.75$, $95 \% \mathrm{CI}[0.57,0.99], p=.046)$ and $2(\mathrm{AOR}=0.75,95 \% \mathrm{CI}$ [0.56, 0.99], $p=.044)$.

Because fathers may overestimate their level of involvement (Coley and Morris 2002), we conducted additional sensitivity analyses to examine outcomes using mothers' reports of father early engagement behaviors. Mothers were asked two of the father early engagement behaviors questions in an identical format (e.g., whether father drove them, whether fathers helped financially) and one similar question about whether fathers visited them at the hospital (not whether they were present at the birth, as fathers were asked). Based on these three items, we created a composite of mother's perception of father early engagement behaviors. This composite was significantly correlated with father's self-reported early engagement behaviors $(r(2592)=0.53, p<.001)$. To test the reliability of their observations on the identically worded items, we subjected parents' responses regarding whether fathers contributed financially and provided other instrumental help (e.g., driving to the clinic) to an interrater reliability analysis to quantify their level of agreement. Parents' observations of fathers' financial contribution were not reliable $($ Kappa $=.31)$ nor were their reports of instrumental help (Kappa $=.42)$. In addition, we ran the logistic regression models with mothers' perceptions of fathers' early engagement behaviors as an independent variable. Results suggested that mothers' reports of father early engagement behaviors were a weaker predictor of $\mathrm{LBW}(\mathrm{AOR}=0.82$,
Fig. 1 Father early engagement behaviors are associated with lower predicted probability of infant low birth weight (LBW). Note $2.6 \%$ of fathers engaged in 0 behaviors; $6.5 \%$ in 1 behavior; $22 \%$ in 2 behaviors; $68.9 \%$ engaged in all 3 early engagement behaviors

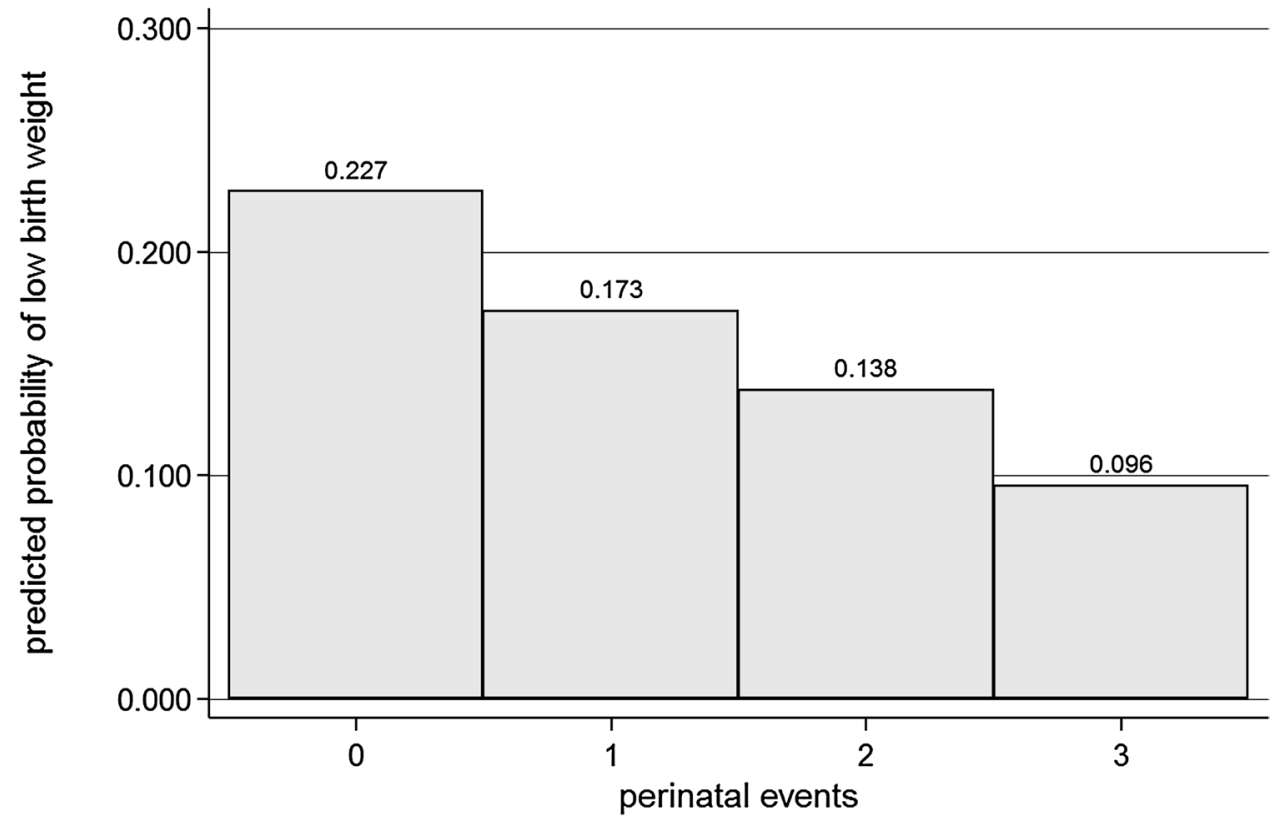


95\% CI [0.66, 1.01], $p=.062$ ) when compared to fathers' self-report. When entering them simultaneously into the logistic regression, fathers' self-reports (and not mothers' reports, $p=.91, n s)$ of their early engagement predicted LBW $(\mathrm{AOR}=0.77,95 \%$ CI $[0.63,0.93], p=.008)$.

\section{Discussion}

This study focused on fathers' early engagement behaviors during the perinatal period, which includes the time period up to 7 days after the child's birth, because little is known about fathers' engagement in fragile families during this important time. Most unmarried fathers engaged in $2(22 \%)$ or $3(68.9 \%)$ early engagement behaviors, such as giving the baby's mother money to buy things for the baby, helping with transportation or chores, and being present at the birth. Though lower levels of engagement were rare, a nontrivial fraction of fathers $(9.1 \%)$ engaged in 0 or 1 early engagement behaviors. The predicted probability of LBW among the $9.1 \%$ of fathers who engaged in 1 or 0 early behaviors was more than double the national rate of $8.03 \%$ of all US infants (Martin et al. 2015).

One prior study using FFCWS data found that maternal perceptions of fathers' early engagement were generally associated with better maternal and infant outcomes, but this study did not find a direct association of fathers' engagement behaviors on infant LBW (Teitler 2001). That study used maternal report of fathers' behaviors, rather than fathers' self-reports. Prior FFCWS studies suggest that mothers' reports of father involvement are lower than fathers' reports (Mikelson 2008). Another study that compared low-income mothers' and fathers' reports of father involvement found that although mothers' and fathers' reports were highly correlated, fathers consistently reporter higher levels of their involvement than did mothers (Coley and Morris 2002). Report consistency was much higher among co-residing parents. In addition, parents who reported higher relationship conflict were less likely to agree on the level of father involvement (Coley and Morris 2002).

Our findings were consistent with these prior studies showing discrepant reporting patterns for mothers and fathers. We found modest correlation between fathers' and mothers' reports of father early engagement behaviors, however, this may not be surprising given that the items asked of fathers and mothers were not an identical match. Consistent with prior studies, our results comparing fathers' and mothers' reports of father early engagement behaviors suggested that mothers and fathers judged father's engagement differently. The results suggested that mothers' perceptions of father early engagement behaviors were a weaker predictor of LBW, and when entering both fathers' and mothers' perceptions simultaneously into the logistic regression, father's reports-and not mothers' reports-predicted LBW.

With no clear unbiased source of data, our final models (Table 3) used fathers' self-reports. Using self-reported data from unmarried fathers, our analyses indicated that LBW occurs less frequently in families where fathers also report higher paternal engagement. The findings of the current study, which show that positive father engagement may be beneficial to infant wellbeing, echo those of Bloch and colleagues (Bloch et al. 2010). In their study of unmarried pregnant women, they found a dose-response association between mother-father relationship quality and maternal and infant health, with better quality relationships associated with lowered risk for negative outcomes, including infant low birth weight (Bloch et al. 2010). Our study extends those findings by focusing on fathers' concrete support to the mother during pregnancy, while accounting for maternal report of relationship quality. On the whole, these studies suggest that mothers' perception of fathers' greater involvement is generally associated with better health outcomes (Teitler 2001), and lower levels of early engagement is correlated with LBW.

Results of these studies suggest that fathers may influence infant wellbeing by providing both tangible resources and emotional support to their partner during the perinatal period. The parents in the current study were unmarried and, on average, were young and low-income. Particularly among unmarried women and low-income women who experience high levels of allostatic load, a partner who provides material resources and shows engagement may reduce maternal stress (Bloch et al. 2010). One prior study showed that maternal perceptions of paternal support during pregnancy seemed to lessen the effects of chronic stress, and was correlated with lower levels of preterm births (Ghosh et al. 2010).

In addition to the direct benefits of tangible resources, relatively simple behaviors, such as helping with transportation or chores or giving the mother money to buy things for the baby, may signal commitment to the mother and baby (Tach et al. 2010). Such commitment or emotional support may be especially beneficial to reduce stress experienced by low-income mothers, perhaps more so than would be the case in other settings or contexts. As discussed in the Limitations section, our measure may additionally be acting as a proxy for other aspects of fathers' engagement and support to his partner that are not directly tapped by the current measure of early engagement, but are nonetheless correlated with benefits for mothers and infants.

\section{Implications for Intervention}

Most unmarried parents are in a relationship at the time of their child's birth (Tach et al. 2010), and both men and women express the desire for father involvement 
(Gibson-Davis et al. 2005). The transition to parenthood has been described as a "magic moment" in which fathers can become highly engaged (Walsh et al. 2014). However, fathers are not generally included in education or intervention during pregnancy. This may be a missed opportunity.

Research shows that even unmarried fathers have high rates of attendance at prenatal visits such as ultrasounds (Walsh et al. 2017), and fathers' engagement in such visits increases maternal health engagement (Redshaw and Henderson 2013). Such prenatal health care visits may be an opportunity to engage fathers and provide anticipatory guidance and psychosocial interventions-for example, counseling fathers on how to support their partner during pregnancy, providing anticipatory guidance regarding caring for an infant, and underscoring the important role fathers play in promoting infant health and wellbeing.

\section{Study Limitations}

Whereas prior research relied on mothers' perceptions of fathers' early engagement (Teitler 2001), we used fathers' self-reports of their early engagement behaviors. The link between fathers' early engagement behaviors and birth weight outcomes was maintained in analyses that assessed different measurement of early engagement. However, it is important to note study limitations. The analyses presented herein are correlational and should not be interpreted to indicate that lack of fathers' early engagement behaviors caused LBW. Although we account for numerous potential confounders, other unobserved factors (e.g., material hardship) are not fully captured in the current models and may be jointly predictive of fathers' early engagement behaviors and LBW. Furthermore, due to missing data, our results cannot be interpreted as generalizable to the FFCWS as a whole. For example, Table 1 illustrates that our analytic sample was younger (fathers) and had higher household income, compared to the full sample of nonmarried parents in FFCWS.

In addition, all of our measures are self-reported, raising the potential for recall bias, e.g., individuals may not accurately recall their behaviors. Furthermore, social desirability concerns likely influence report of behaviors such as substance use and may also influence report of other health behaviors such as self-rated health. The scales assessing relationship quality had relatively low alphas, which may have been influenced by the low number of items in the two subscales.

Finally, our measure of fathers' early engagement behaviors assessed a limited range of fathers' potentially supportive behaviors during pregnancy. Because this study consisted of secondary data analysis, we were limited to the available variables that assessed fathers' early engagement during the perinatal period specifically. Also we chose to use self-reported data from fathers, which also limited the availability of data. Given the timing of the item related to fathers' presence at birth, it is unlikely to be a direct predictor of LBW per se, and in the current analysis, this item is most likely acting as a proxy for fathers' preconceptional and prenatal engagement more broadly.

\section{Future Research}

Future research should explore these relationships using data that more fully measure fathers' early engagement behaviors, and account for the influence of unobserved variables not measured in the current study. Future research could examine the mechanisms by which fathers' early engagement behaviors may influence maternal health. For example, one mechanism by which fathers may impact infant health is through their influence on maternal health behaviors, such as engaging in smoking cessation with their partner, which is linked to birth outcomes (Misra et al. 2010).

\section{Conclusion}

In a high-risk sample of unmarried parents, most fathers engaged in at least three early engagement behaviors. Although lows levels of paternal early engagement were relatively uncommon, with $9.1 \%$ of fathers reporting they engaged in 1 or no early engagement behaviors measured in this study, low engagement was associated with double the predicted probability of having a LBW infant. Results suggested that increasing fathers' engagement and support to his partner during pregnancy may be one mechanism by which to promote maternal and infant health outcomes.

Funding The Fragile Families and Child Wellbeing Study is supported by the Eunice Kennedy Shriver National Institute of Child Health and Human Development through Grants R01HD36916, R01HD39135, and R01HD40421 and a consortium of private foundations (http:// www.fragilefamilies.princeton.edu/funders.asp). The authors of this study did not obtain funding for the analyses reported herein.

\section{Compliance with Ethical Standards}

Conflict of interest The authors have no financial relationships relevant to this article to disclose. The authors have no conflicts of interest to disclose.

Ethical Approval This study was reviewed by the University of Michigan Institutional Review Board. As secondary data analysis, this study was deemed exempt from oversight.

\section{References}

Aizer, A., \& Currie, J. (2014). The intergenerational transmission of inequality: Maternal disadvantage and health at birth. Science, 344(6186), 856-861. https://doi.org/10.1126/science.1251872. 
Alio, A. P., Bond, M. J., Padilla, Y. C., Heidelbaugh, J. J., Lu, M., \& Parker, W. J. (2011). Addressing policy barriers to paternal involvement during pregnancy. Maternal Child Health Journal, 15(4), 425-430. https://doi.org/10.1007/s10995-011-0781-1.

Alio, A. P., Mbah, A. K., Grunsten, R. A., \& Salihu, H. M. (2011). Teenage pregnancy and the influence of paternal involvement on fetal outcomes. Journal of Pediatric Adolescent Gynecology, 24, 404-409. https://doi.org/10.1016/j.jpag.2011.07.002.

Bloch, J. R., Webb, D. A., Matthews, L., Dennis, E. F., Bennett, I. M., \& Culhane, J. F. (2010). Beyond marital status: The quality of the mother-father relationship and its influence on reproductive health behaviors and outcomes among unmarried low income pregnant women. Maternal and Child Health Journal, 14, 726-734.

Boardman, J. D., Powers, D. A., Padilla, Y. C., \& Hummer, R. A. (2002). Low birth weight, social factors, and developmental outcomes among children in the United States. Demography, 39(2), 353-368. https://doi.org/10.1353/dem.2002.0015.

Bond, M. J. (2010). The missing link in MCH: Paternal involvement in pregnancy outcomes. American Journal of Men's Health, 4(4), 285-286. https://doi.org/10.1177/1557988310384842.

Bronfenbrenner, U. (1979). The ecology of human development: Experiments by nature and design. Cambridge, MA: Harvard University Press.

Carlson, M. J., \& McLanahan, S. S. (2002). Fragile families, father involvement and public policy. In C. S. Tamis-LeMonda \& N. Cabrera (Eds.), Handbook of father involvement: Multidisciplinary perspectives (pp. 461-488). Mahwah: Lawrence Erlbaum Associates.

Castillo, J., Welch, G., \& Sarver, C. (2011). Fathering: The relationship between fathers' residence, fathers' sociodemographic characteristics, and father involvement. Maternal and Child Health Journal, $15,1342-1349$.

Chamberlain, C., O'Mara-Eves, A., Oliver, S., Caird, J. R., Perlen, S. M., Eades, S. J., \& Thomas, J. (2013). Psychosocial interventions for supporting women to stop smoking in pregnancy. The Cochrane Database of Systematic Reviews, 10, CD001055. https ://doi.org/10.1002/14651858.CD001055.pub4.

Coley, R. L., \& Morris, J. E. (2002). Comparing father and mother reports of father involvement among low-income minority families. Journal of Marriage and Family, 64(4), 982-998.

Conley, D., \& Bennett, N. G. (2000). Is biology destiny? Birth weight and life chances. American Sociological Review, 65(3), 458-467. https://doi.org/10.2307/2657467.

DeSalvo, K. B., Bloser, N., Reynolds, K., He, J., \& Muntner, P. (2006). Mortality prediction with a single general self-rated health question. Journal of General Internal Medicine, 21(3), 267-275. https ://doi.org/10.1111/j.1525-1497.2005.00291.x.

Dubowitz, H., Black, M. M., Cox, C. E., Kerr, M. A., Litrownik, A. J., Radhakrishna, A., Runyan, D. K. (2001). Father involvement and children's functioning at age 6 years: A multisite study. Child Maltreatment, 6(4), 300-309.

Dunkel-Schetter, C., \& Tanner, L. (2012). Anxiety, depression and stress in pregnancy: Implications for mothers, children, research, and practice. Current Opinion Psychiatry Journal, 25(2), 141148. https://doi.org/10.1097/YCO.0b013e3283503680.

Fulda, K. G., Kurian, A. K., Balyakina, E., \& Moerbe, M. M. (2014). Paternal race/ethnicity and very low birth weight. BMC Pregnancy and Childbirth, 14, 385-389. https://doi.org/10.1186/s1288 4-014-0385-z.

Ghosh, J. K. C., Wilhelm, M. H., Dunkel-Schetter, C., Lombardi, C. A., \& Ritz, B. R. (2010). Paternal support and preterm birth, and the moderation of effects of chronic stress: A study in Los Angeles County mothers. Archives Womens Mental Health, 13, 327-338. https://doi.org/10.1007/s00737-009-0135-9.

Gibson-Davis, C. M., Edin, K., \& McLanahan, S. (2005). High hopes but even higher expectations: The retreat from marriage among low-income couples. Journal of Marriage and Family, 67, 1301-1312.

Hamilton, B. E., Martin, J. A., \& Ventura, S. J. (2012). Births: Preliminary data for 2011. National Vital Statistics Reports, 61(5), 1-20.

Hobel, C. J., Goldstein, A., \& Barrett, E. S. (2008). Psychosocial stress and pregnancy outcome. Clinical Obsterics and Gynecology, 51(2), 333-348. https://doi.org/10.1097/GRF.0b013e31816f2709.

Hux, V. J., Calov, J. M., \& Roberts, J. M. (2014). Allostatic load in women with a history of low birth weight infants: The National Health and Nutrition Examination Survey. Journal of Women's Health, 23(12), 1039-1045. https://doi.org/10.1089/ jwh.2013.4572.

IBM Corporation. (2014). IBM SPSS Statistics for Windows, Version 23.0. Armonk: IBM Corporation.

Idler, E. L., \& Angel, R. J. (1990). Self-rated health and mortality in the NHANES-I Epidemiologic Follow-up Study. American Journal of Public Health, 80(4), 446-452. https://doi.org/10.2105/ ajph.80.4.446.

Idler, E. L., \& Benyamini, Y. (1997). Self-rated health and mortality: A review of twenty-seven community studies. Journal of Health and Social Behavior, 38(1), 21-37. https://doi.org/10.2307/2955359.

Jeynes, W. H. (2014). A meta-analysis: The relationship between father involvement and student academic achievement. Urban Education, 50: 387-423

Lewin, A., Mitchell, S. J., Waters, D., Hodgkinson, S., Southammakosane, C., \& Gilmore, J. (2015). The protective effects of father involvement for infants of teen mothers with depressive symptoms. Maternal and Child Health Journal, 19, 1016-1023.

Long, J. S., \& Freese, J. (2005). Regression models for categorical outcomes using Stata (2nd ed.). College Station: Stata Press.

Lu, M. C., Jones, L., Bond, M. J., Wright, K., Pumpuang, M., Maidenberg, M.,.. . Rowley, D. L. (2010). Where is the F in MCH? Father involvement in African American families. Ethnicity and Disease, 20, S2-49-61.

Ma, S. (2008). Paternal race/ethnicity and birth outcomes. American Journal of Public Health, 98(12), 2285-2292. https://doi. org/10.2105/AJPH.2007.117127.

Malin, G. L., Morris, R. K., Riley, R., Teune, M. J., \& Khan, K. S. (2014). When is birthweight at term abnormally low?A systematic review and meta-analysis of the association and predictive ability of current birthweight standards for neonatal outcomes. BJOG, 121, 515-526. https://doi.org/10.1111/1471-0528.12517.

Martin, J. A., Hamilton, B. E., Osterman, M. J. K., Curtin, S. C., \& Mathews, T. J. (2015). Division of vital statistics births: Final data for 2013. National Vital Statistics Reports, 64, 1-65.

Mathews, T. J., \& MacDorman, M. F. (2013). Infant mortality statistics from the 2010 period linked birth/ infant death data set. National Vital Statistics Reports, 62(8), 1-26.

McLanahan, S. S., Garfinkel, I., Reichman, N., Teitler, J., Carlson, M. J., \& Audigier, C. N. (2003). The fragile families and child wellbeing study: Baseline national report. Princeton: Princeton University

Mikelson, K. S. (2008). He said, she said: Comparing mother and father reports of father involvement. Journal of Marriage and Family, 70, 613-624.

Misra, D. P., Caldwell, C., Young, A. A. Jr., \& Abelson, S. (2010). Do fathers matter? Paternal contributions to birth outcomes and racial disparities. American Journal of Obsterics and Gynecology, 202(2), 99-100. https://doi.org/10.1016/j.ajog.2009.11.031.

Ngui, E., Cortright, A., \& Blair, K. (2009). An investigation of paternity status and other factors associated with racial and ethnic disparities in birth outcomes in Milwaukee, Wisconsin. Maternal Child Health Journal, 13, 467-478. https://doi.org/10.1007/s1099 5-008-0383-8.

Redshaw, M., \& Henderson, J. (2013). Fathers' engagement in pregnancy and childbirth: Evidence from a national 
survey. BMC Pregnancy and Childbirth, 13, 70-85. https://doi. org/10.1186/1471-2393-13-70.

Reichman, N. E., Hamilton, E. R., Hummer, R. A., \& Padilla, Y. C. (2008). Racial and ethnic disparities in low birthweight among urban unmarried mothers. Maternal Child Health Journal, 12, 204-215. https://doi.org/10.1007/s10995-007-0240-1.

Reichman, N. E., \& Teitler, J. O. (2006). Paternal age as a risk factor for low birthweight. American Journal of Public Health, 96(5), 862-866. https://doi.org/10.2105/AJPH.2005.066324.

Reichman, N. E., Teitler, J. O., Garfinkel, I., \& McLanahan, S. S. (2001). Fragile families: Sample and design. Children and Youth Services Review, 23, 303-326.

Stotts, A. L., Northrup, T. F., Schmitz, J. M., Green, C., Tyson, J., Velasquez, M. M., \& Hovell, M. F. (2013). Baby's Breath II protocol development and design: A secondhand smoke exposure prevention program targeting infants discharged from a neonatal intensive care unit. Contemporary Clinical Trials, 35, 97-105. https://doi.org/10.1016/j.cct.2013.02.012.

Tach, L., Mincy, R., \& Edin, K. (2010). Parenting as a "package deal": Relationships, fertility, and nonresident father involvement among unmarried parents. Demography, 47(1), 181-204.

Tan, H., Wen, S. W., Walker, M., \& Demissie, K. (2004). Missing paternal demographics: A novel indicator for identifying high risk population of adverse pregnancy outcomes. BMC Pregnancy and Childbirth, 4, 21-27. https://doi.org/10.1186/1471-2393-4-21.
Taylor, C. A. L., \& Sarathchandra, D. (2015). Migrant selectivity or cultural buffering? Investigaing the Black immigrant health advantage in low birth weight. Journal of Immigrant and Minority Health. https://doi.org/10.1007/s10903-015-0194-0.

Teitler, J. O. (2001). Father involvement, child health and maternal health behavior. Children and Youth Services Review, 23(4/5), $403-425$.

Viera, A. J. (2008). Odds ratios and risk ratios: What's the difference and why does It matter? Southern Medical Journal, 101, 730-734.

Waldfogel, J., Craigie, T., \& Brooks-Gunn, J. (2010). Fragile families and child wellbeing. The Future of Children, 20(2), 87-112. https ://doi.org/10.1353/foc.2010.0002.

Walsh, T. B., Tolman, R. M., Davis, R. N., Palladino, C. L., Romero, V. C., \& Singh, V. (2014). Moving up the "magic moment": Fathers' experience of prenatal ultrasound. Fathering, 12(1), 18-37.

Walsh, T. B., Tolman, R. N., Singh, V., Davis, M. M., \& Davis, R. N. (2017). Expectant fathers' presence at prenatal ultrasounds: An opportunity for engagement. Social Work Research, 41, 181-185.

Witt, W. P., Cheng, E. R., Wisk, L. E., Litzelman, K., Chatterjee, D., Mandell, K., \& Wakeel, F. (2014). Maternal stressful life events prior to conception and the impact on infant birth weight in the United States. American Journal of Public Health, 104(1), S81S89. https://doi.org/10.2105/AJPH.2013.301544. 